\title{
SPRAWOZDANIE Z DZIAŁALNOŚCI NAUKOWO-DYDAKTYCZNEJ INSTYTUTU LITURGIKI I HOMILETYKI KUL W ROKU AKADEMICKIM 2018/2019
}

\section{ETATOWI PRACOWNICY INSTYTUTU (10)}

Nauczyciele akademiccy zatrudnieni na stanowisku:

- profesora zwyczajnego: ks. Stanisław Dyk, ks. Zdzisław Janiec;

- profesora nadzwyczajnego: ks. Bogusław Migut, ks. Waldemar Pałęcki, ks. Piotr Kulbacki, Michał Wyrostkiewicz;

- adiunkta: ks. Zbigniew Głowacki, ks. Michał Klementowicz; ks. Andrzej Megger; - asystenta: ks. Tomasz Lisiecki.

Nauczyciele akademiccy posiadajacy tytuł profesora: ks. Stanisław Dyk, ks. Zdzisław Janiec.

Nauczyciele akademiccy posiadający stopień naukowy doktora habilitowanego: ks. Stanisław Dyk, ks. Zdzisław Janiec, ks. Piotr Kulbacki, ks. Bogusław Migut, ks. Waldemar Pałęcki, Michał Wyrostkiewicz.

Nauczyciele akademiccy posiadający stopień naukowy doktora: ks. Zbigniew Głowacki, ks. Michał Klementowicz, ks. Tomasz Lisiecki, ks. Andrzej Megger.

Liczba katedr:

- Katedra Teologii Liturgii

- Katedra Historii Liturgii

- Katedra Homiletyki 


\section{PRACE NAUKOWE}

\section{A. MONOGRAFIE}

DYK S., Program duszpasterski Kościoła w Polsce na rok 2017/2018: „Jesteśmy napełnieni Duchem Świętym”. Zeszyt homiletyczny, Instytut Gość Media, Katowice 2018, ISBN: 978-83-950701-2-9, ss. 135.

Migut B., Liturgia jako teologia żywa, Wydawnictwo KUL, Lublin 2019, ISBN 978 83-8061-660-8, ss. 248.

\section{Autorstwo rozdziału w monografii}

DYK S., Cechy świętości, czyli style ewangelizacji w świecie współczesnym, w: Radość świętości: chrześcijańskie świadectwo we współczesnym świecie, red. S. Klimas, Wydawnictwo „Jedność”, Kielce 2019, s. 85-101.

DYK S., Dyk Stanisław ks., w: Encyklopedia 100-lecia KUL, t. 1, Lublin 2018, s. 187-188.

DYK S., Family Retreats, in: Catholic Family Ministry. The Scientific Reflection and the Pratcical Ministry of the Church, ed. Jacek Goleń, Wydawnictwo KUL, Lublin 2018, s. 317-328.

DYK S., Homilia wprowadzeniem w doświadczenie Ducha Świętego, w: Program duszpasterski Kościoła w Polsce na rok 2018/2019 „W mocy Ducha Świętego”. Zeszyt teologicznopastoralny, red. J. Bartoszek, R. Chromy, K. Piechaczek, Katowice 2018, s. 23-32.

DYK S., Instytut Liturgiki i Homiletyki, w: Encyklopedia 100-lecia KUL, t. 1, Lublin 2018, s. 361-364 [współautorstwo z B. Migut].

DYK S., Kudasiewicz Józef, ks. 1926-2012 biblista, teolog, tłumacz, w: Encyklopedia 100-lecia KUL, t. 1, Lublin 2018, s. 590-591.

DYK S., Przegląd Homiletyczny, w: Encyklopedia 100-lecia KUL, t. 2, Lublin 2018, s. 228-229.

GŁOWACKI Z., Roczniki Liturgiczno-Homiletyczne, w: Encyklopedia 100-lecia KUL, t. 2, Lublin 2018, s. 358.

GŁOWACKI Z., Rok liturgiczny w rekolekcjach Ruchu Światło-Życie, w: Ruch Światło-Życie w służbie Kościołowi, red. D. Czaicki, Kraków 2018, s. 73-87.

KLEMENTOwiCz M., Miejsce literatury w budowaniu tekstu homilii. Analiza na przykładzie przepowiadania arcybiskupa Alfonsa Nossola, w: Słowo - kaznodziejskie i literackie, red. J. Sikora, Warszawa 2018, s. 131-149.

Kulbacki P., Danielski Wojciech, w: Encyklopedia 100-lecia KUL, t. 1, Lublin 2018, s. 142-143.

KULBACKI P., Eklezjologia eucharystyczna, w: Eucharystia - tajemnica celebrowana (Studia Liturgiczne, t. 14), red. W. Pałęcki, A. Megger, Lublin 2018, s. 11-20.

KUlBACKI P., Eklezjologia posług i funkcji liturgicznych laikatu, w: Quia fecit mihi magna... Księga pamiątkowa dedykowana ks. profesorowi Czesławowi Krakowiakowi z okazji złotego jubileuszu kapłaństwa, red. Z. Głowacki, A. Megger, Lublin 2019, s. 163-173.

KULBACKI P., Instytut Formacji Pastoralno-Liturgicznej, w: Encyklopedia 100-lecia KUL, Lublin 2018, t. 1, s. 352-353. 
KULBACKI P., Wartość postanowień i przyrzeczeń w drodze do wolności osobistej, w: W trosce o wolność, red. T. Bronakowski, Warszawa 2019, s. 252-264.

MEGGER A., Nieodkryty dokument: „Compendium eucharisticum” (2009), w: Eucharystia - tajemnica celebrowana (Studia Liturgiczne, t. 14), red. W. Pałęcki, A. Megger, Lublin 2018, s. 115-131.

MegGer A., Odkryć Nieznanego. Duch Święty sprawcą liturgii, w: Zbawczy dialog z Bogiem w liturgicznych znakach (Colloquia Disputationes 43), red. D. Kwiatkowski, Poznań 2018, s. 57-69.

MegGer A., Studia Liturgiczne, w: Encyklopedia 100-lecia KUL, t. 1, Lublin 2018, s. 399.

MiguT B., Instytut Liturgiki i Homiletyki, w: 100 lat teologii na KUL, red. S. Nowosad, J. Mastej, Lublin 2018, s. 117-131.

Migut B., Ks. prof. dr hab. Czesław Krakowiak - Życie i działalność dydaktyczno-naukowa do 2018 roku, w: Quia fecit mihi magna... Księga pamiątkowa dedykowana ks. profesorowi Czesławowi Krakowiakowi z okazji złotego jubileuszu kapłaństwa, red. Z. Głowacki, A. Megger, Lublin 2019, s. 23-37.

Migut B., Misteryjna natura liturgii, w: Język w liturgii, red. B. Drabik, W. Przyczyna, Tarnów 2018, s. 11-37.

Migut B., Nowe kierunki sakramentologii, w: Znaki tajemnicy. Sakramenty w teorii i praktyce Kościoła, red K. Porosło, R. Woźniak, Kraków 2018, s. 95-122.

Migut B., Wiara i chrzest, w: Quia fecit mihi magna... Księga pamiątkowa dedykowana ks. profesorowi Czesławowi Krakowiakowi z okazji złotego jubileuszu kapłaństwa, red. Z. Głowacki, A. Megger, Lublin 2018, s. 225-238.

PAŁĘCKI W., „Życie twoich wiernych, o Panie, zmienia się, ale się nie kończy”. Paschalny charakter nadziei chrześcijańskiej w liturgii pogrzebowej, w: Jest nadzieja, bo jest życie wieczne, red. B. Kulik, W. Pałęcki, Lublin 2018, s. 31-47.

PAŁECKI W., Instytut Liturgiki i Homiletyki. Katedra Historii Liturgii, w: Encyklopedia 100-lecia KUL, t. 1, Lublin 2018, s. 362.

PAŁĘCKI W., Mistagogiczny wymiar formacji seminaryjnej, w: Quia fecit mihi magna... Księga pamiątkowa dedykowana Księdzu Profesorowi Czesławowi Krakowiakowi z okazji złotego jubileuszu kapłaństwa, red. Z. Głowacki, A. Megger, Lublin 2018, s. 255-286.

PAŁĘCKI W., Wit Zbigniew, w: Encyklopedia 100-lecia KUL, t. 2, Lublin 2018, S. 541-542.

PAŁĘCKI W., Wprowadzenie, w: Eucharystia - Tajemnica celebrowana (Studia liturgiczne, t. 14), red. W. Pałęcki, A. Megger, Lublin 2018, s. 7-10.

WYROSTKIEWICZ M., Nauka rodzi się w dialogu, w: Освіта і наука у сфері національної безпеки: проблеми та пріоритети розвитку, red. М. Романов, National University „Ostroh Academy”, Ostroh 2018, s. 26-27.

WyrostKiEwiCZ M., Sztuka komunikacji - eksploracje infoetyczne, w: Pulchrum et Communicatio. Księga jubileuszowa Profesora Karola Klauzy, red. A. WójciszynWasil, M.J. Gondek, D. Wadowski, Lublin 2018, s. 159-170.

WyrostKIEWICZ M., Wokół ekologii Mszy świętej, w: Quia fecit mihi magna... Księga pamiątkowa dedykowana Księdzu Profesorowi Czesławowi Krakowiakowi 
z okazji złotego jubileuszu kapłaństwa, red. Z. Głowacki, A. Megger, Lublin 2018, s. 337-351.

\section{B. ARTYKUŁY W CZASOPISMACH}

DYK S., Eschatologia jako treść homilii, „Roczniki Teologiczne” 65(2018), z. 12, s. $45-56$.

DYK S., Homiletyka - teologia w służbie ewangelizacji, „Teologia - Kultura - Społeczeństwo" 5(2019), nr 4, s. 63-76.

DYK S., Kontemplacja Chrystusa w słowie i ludzie Bożym jako przygotowanie do homilii, „Kielecki Przegląd Diecezjalny” 44(2018), nr 1, s. 152-163.

DYK S., Pełnia życia kapłańskiego to życie pełne Ducha, „Kielecki Przegląd Diecezjalny" 44(2018), nr 4, s. 738-747.

DYK S., Problematyka cierpienia w przepowiadaniu homilijnym, „Kieleckie Studia Teologiczne" 17(2018), s. 22-38.

GŁOWACKI Z., Duchowość eucharystyczna, „Roczniki Teologiczne” 65(2018), z. 8, s. 27-38.

KLementowicz M., Delimitacja w posłudze słowa Bożego, „Roczniki Teologiczne” 65(2018), z. 12, s. 89-99.

KLementowicz M., Głoszenie słowa Bożego podstawowym zadaniem kapłana, „Sympozjum” 35(2018), z. 2, s. 61-75.

KULBACKI P., Formulas for the Universal Prayer in the Typical Editions of the PostConciliar Missal, „Roczniki Teologiczne” 66(2019), z. 8, s. 64-71.

LISIECKI T. Formacja muzyczna wiernych Kościoła w Polsce według dokumentów synodalnych po Soborze Watykańskim II, „Roczniki Teologiczne” 65(2018), z. 8, s. 77-89.

LISIECKI T., Psalm responsoryjny integralną częścią liturgii słowa, „Studia Redemptorystowskie" 16(2018), s. 217-226.

Migut B., Liturgiczna perspektywa teologii, „Roczniki Teologiczne” 65(2018), z. 8, s. 91-105.

PAŁEৃCKI W., „Canon Missae” w alegorycznej interpretacji Ruperta z Deutz OSB, „Roczniki Teologiczne” 65(2018), z. 8, s. 107-124.

C. ODDANE DO DRUKU

DYK S., Dignity in suffering, w: Godność w cierpieniu - bliskość w umieraniu miłość w żałobie. Studium interdyscyplinarne (Publikacja anglojęzyczna), red. M. Kalinowski, Seton Hall University, USA 2018.

DYK S., Działanie Ducha Świętego w Eucharystii a przepowiadanie homilijne, „Polonia Sacra" 2019.

DYK S., Misterium Objawienia Pańskiego jako treść homilii, „Roczniki Teologiczne” 66(2019), z. 12.

DYK S., Słowo aktualne. Przepowiadanie a kwestie społeczne, Gorzów Wielkopolski: Wydawnictwo Naukowe Akademii im. Jakuba z Paradyża 2019 [monografia].

Klementowicz M., Procesualność w tekście homilii, „Seminare. Poszukiwania naukowe" 2019. 
Klementowicz M., The Affective and Volitional Dimension of Preaching as a Way to Effectively Communicate with People in Danger of Death, w: Godność w cierpieniu - bliskość w umieraniu - miłość w żałobie. Studium interdyscyplinarne (Publikacja anglojęzyczna), red. M. Kalinowski, Seton Hall University, USA 2019.

Kulbacki P., Chrzest sakramentem wiary w wypowiedziach Jana Pawła II, „Studia Pastoralne" 15(2019).

KulbaCKI P., The Concluding Rites in Typical Editions of the Missal of Paul VI, „Roczniki Teologiczne” 66(2019), z. 8.

LISIECKI T., Odnowa kultury muzycznej Kościoła lubelskiego w czasach posługi biskupiej Stefana Wyszyńskiego, „Roczniki Teologiczne”66(2019), z. 8.

MegGer A., Impositio manuum w liturgii sakramentu bierzmowania, ,Roczniki Teologiczne" 66(2019), z. 8.

MegGer A., Sakramenty inicjacji chrześcijańskiej w parafii, Wyd. KUL, Lublin 2019.

Migut B., Eucharystia sakramentem chrześcijańskiej inicjacji. Aspekt teologicznoliturgiczny, „Liturgia Sacra” 25(2019), z. 2.

Migut B., The Eucharist as a Sacrament of Christian Initiation: Historical-Liturgical Aspects, „Roczniki Teologiczne” 66(2019), z. 8.

PAŁECKI W., Erem kamedulski jako miejsce rozbrzmiewającej Laudis perennis, [rozdział w monografii].

PAŁECKI W., Misterium Eucharystii w świetle katechez $\mathrm{z}$ agendy ks. Hieronima Powodowskiego a echa Soboru Trydenckiego, „Roczniki Teologiczne” 66(2019), z. 8.

PAŁĘCKI W., Misterium Najświętszego Imienia Jezus w liturgii Kościoła rzymskiego, „Poznańskie Studia Teologiczne” 2019.

WyrostKIEWICZ M., Ecology of the Mass, „Theologos” 21(2019), nr 1.

WYROSTKIEWICZ M., Liturgia jako przestrzeń przemiany człowieka. Liturgika a teologia moralna, w: Studia Liturgiczne, t. 15, red. W. Pałęcki, A. Megger, Towarzystwo Naukowe KUL, Lublin 2019.

WYROSTKIEWICZ M., Uniwersytet jako przestrzeń rozwoju integralnego człowiekaosoby, „Zeszyty Naukowe KUL” 62(2019), nr 2.

\section{SYMPOZJA, SESJE, KONFERENCJE (ORGANIZACJA I WSPÓŁORGANIZACJA)}

- Konferencja naukowa: „Wznoszona będzie jedna i ta sama modlitwa wonniejsza od jakiegokolwiek kadzidła" (Paweł VI), KUL, 16 maja 2019 r.

- 55. Sympozjum Wykładowców Liturgiki na Wydziałach Teologicznych i w Wyższych Seminariach Duchownych: „Poszukiwanie prawdy nigdy się nie kończy" (Jan Paweł II, Fides et Ratio). Liturgia w relacji do nauk pozateologicznych, Siedlce, 10-12 września 2019 r.

- Konferencja ogólnopolska: „Głoszenie w mocy Ducha Świętego”, Nałęczów, 7-9 października $2018 \mathrm{r}$. 
- Międzynarodowa konferencja: „Klub społeczeństwo: przepowiadanie wobec spraw społecznych”, Katowice, 26 kwietnia 2019 r.

- Międzynarodowa konferencja naukowa: „Media - Cooperation - Communication”, KUL, 11 października 2018.

- Międzynarodowa konferencja: „Męczeństwo, pamięć, świadectwo. 100 rocznica męczeńskiej śmierci ks. Cyryla Bujalskiego (1887-1919)”, Czercze (Podole, Ukraina), 14 marca 2019 r.

- Konferencja naukowa: „Parafia środowiskiem rozeznawania powołania”, Łódź, 8-11 października 2018 r.

- Konferencja naukowa: „Wolni i wyzwalający”, Częstochowa, 23-24 lutego 2019 r.

\section{PRZEWODY NAUKOWE}

\section{A. ROZPRAWY DOKTORSKIE}

DYK Stanisław (promotor): ks. Leszek Sztandera, Teandryczny wymiar świętości chrześcijańskiej w przepowiadaniu biskupa Kazimierza Ryczana. Studium homiletyczne, 24.09.2019.

DYK Stanisław (promotor): ks. Michał Orzoł, Mistagogia chrystofanii paschalnych (J 20,1-9.19.-21,9). Studium homiletyczne na przykładzie transmisji Mszy Świętych w polskim radiu i telewizji, 23.09.2019.

DYK Stanisław (promotor): ks. Remigiusz Malewicz, Wielki Post jako „czas na odnowienie łask chrzcielnych" (DH 69). Studium homiletyczne na przykładzie polskiego przepowiadania posoborowego, 19.06.2019.

DYK Stanisław (promotor): ks. Tomasz Cabaj, Obraz Kościoła przyszłości. Studium homiletyczne na podstawie przepowiadania papieskiego z racji Światowych Dni Młodzieży, 18.06.2019.

JANIEC Zdzisław (promotor): ks. Grzegorz Staszczak, Formacja Kościoła domowego przez liturgię i pobożność ludową w nauczaniu Kościoła po Drugim Soborze Watykańskim, 12.06.2019.

JANIEC Zdzisław (promotor): ks. Radosław Koterbski, Misterium Mszy Świętej w świetle modelu komunikacyjnego Friedemanna Schulza von Thun'a, 11.06.2019.

Migut Bogusław (promotor): ks. Jerzy Biegański, Reforma i odnowa liturgiczna na terenie diecezji grodzieńskiej po Drugim Soborze Watykańskim, 26.09.2019.

\section{B. PRACE LICENCJACKIE I MAGISTERSKIE}

JANIEC Zdzisław: 3 prace magisterskie.

Migut Bogusław: 1 praca magisterska. 


\title{
5. INNE OSIĄGNIĘCIA
}

Dr hab. Michał Wyrostkiewicz, prof. KUL był kierownikiem dwóch i wykonawcą jednego projektu naukowego:

a) Narodowa Agencja Wymiany Akademickiej: 1.10-2018-31.01.2019, projekt pt. „Infocomponent - an element of the natural environment of the human person” realizowany na Uniwersytecie Preszowskim;

b) Ministerstwo ds. Młodzieży i Sportu Ukrainy: 1.09-31.10.2019, tytuł: „Increasing the Competence of Youth in the Field of Journalism as a Platform for the Development of Cooperation between Ukraine and the Republic of Poland" realizowany w Uniwersytecie Narodowym „Akademia Ostrogska” na Ukrainie i na KUL-u.

c) wykonawca: „Narodowe Centrum Badań i Rozwoju: 1.09.2018-30.06.2020, tytuł „Otwarci na sukces”, realizacja - KUL.

\section{KS. BARTOSZ MICHTA}

e-mail: michtabartosz@wp.pl

DOI: http://dx.doi.org/10.18290/rt.2019.66.12-11

\section{SPRAWOZDANIE Z KONFERENCJI NAUKOWEJ PT. „DOBRA NOWINA W MULTIMEDIALNYM ŚWIECIE" \\ Kodeń, 6-8 października 2019 r.}

\begin{abstract}
„Myślę, że musimy przerwać błędne koło niepokoju i spiralę lęku, będące owocem nawyku koncentrowania uwagi na «złych wiadomościach»” - pisał papież Franciszek w Orędziu na 51. Światowy Dzień Środków Społecznego Przekazu. Dlatego też w dniach 6-8 października w Kodniu na Podlasiu, pod hasłem „Dobra Nowina w multimedialnym świecie”, odbyła się konferencja naukowa zorganizowana przez Stowarzyszenie Homiletów Polskich (SHP) we współpracy z Katedrą Homiletyki KUL, Katedrą Komunikacji Religijnej UPJPII oraz Katedrą Teologii Pastoralnej, Liturgiki, Homiletyki i Katechetyki UŚ. Wydarzenie zgromadziło ponad 40 osób (prelegentów i uczestników), którzy reprezentowali razem 16 ośrodków naukowych w Polsce. Konferencję otworzył Przewodniczący SHP ks. prof. dr hab. Henryk Sławiński z UPJPII. W swoim wystąpieniu, nawiązując do głównej myśli tego wydarzenia podkreślił, iż każdy człowiek (szczególnie zaś kapłan)
\end{abstract}

